\title{
BMJ Open Healthcare professionals' perceptions and perspectives on biosimilar medicines and the barriers and facilitators to their prescribing in UK: a qualitative study
}

\author{
Mohammed Ibrahim Aladul,, ${ }^{1,2}$ Raymond William Fitzpatrick, ${ }^{1}$ \\ Stephen Robert Chapman ${ }^{1}$
}

To cite: Aladul MI,

Fitzpatrick RW, Chapman SR. Healthcare professionals' perceptions and perspectives on biosimilar medicines and the barriers and facilitators to their prescribing in UK: a qualitative study. BMJ Open 2018;8:e023603. doi:10.1136/ bmjopen-2018-023603

\section{- Prepublication history for} this paper is available online. To view these files, please visit the journal online (http://dx.doi. org/10.1136/bmjopen-2018023603).

Received 14 April 2018 Revised 25 September 2018 Accepted 26 September 2018

Q Check for updates

(c) Author(s) (or their employer(s)) 2018. Re-use permitted under CC BY-NC. No commercial re-use. See rights and permissions. Published by BMJ.

${ }^{1}$ School of Pharmacy, Keele University, Newcastle-UnderLyme, UK

${ }^{2}$ School of Pharmacy, University of Mosul, Mosul, Iraq

Correspondence to Professor Stephen Robert Chapman; s.r.chapman@keele.ac.uk

\section{ABSTRACT}

Objective To investigate UK healthcare professionals' perceptions and perspectives towards biosimilar infliximab, etanercept and insulin glargine and the potential barriers and facilitators to their prescribing. Design A cross-sectional qualitative study design was used.

Setting Five hospitals within the West Midlands area in UK.

Interventions $30 \mathrm{~min}$ face-to-face, semistructured interviews of healthcare professionals.

Participants 22 healthcare professionals (consultants, nurses and pharmacists) participated in the semistructured interviews.

Outcomes Participants' opinion and attitudes about biosimilars and the barriers and facilitators to the prescribing of infliximab, etanercept and insulin glargine biosimilars in gastroenterology, rheumatology and diabetology specialties.

Results This study showed that UK healthcare professionals had good knowledge of biosimilars and were content to initiate them. Healthcare professionals disagreed with biosimilar auto-substitution at pharmacy level and multiple switching. Subtle differences among healthcare professionals were identified in the acceptance of switching stable patients, indication extrapolation and cost savings sharing.

Conclusion Safety and efficacy concerns, patients' opinion and how cost savings were shared were the identified barriers to considering prescribing biosimilars. Real-life data and financial incentives were the suggested facilitators to increase biosimilar utilisation.

\section{INTRODUCTION}

Biosimilars are an alternative to expensive branded biological regimens. Financial pressures on healthcare systems means increasing the use of biosimilars is becoming more important. As a result, major guidance documents in oncology, haematology, gastroenterology and rheumatology have incorporated biosimilars into recommended

\section{Strengths and limitations of this study}

- This study draws a variety of in-depth accounts from participants of different profession in different specialties to reveal the facilitators and barriers to the use of biosimilars in UK hospitals.

- We use the well-established framework method of qualitative analysis, which allows for comparisons to be made across cases and themes.

- Our approach shows the opinions of those prescribing biosimilars who accepted to take part in the study. This may not be a truly representative sample as it may not include those who were not using biosimilars and/or those healthcare professionals more reluctant to prescribe who may not have received formal training about fundamental of biosimilars.

- While participants represented a variety of professional roles and range of perspectives, they were all recruited from West Midland's hospitals in England and might therefore not be representative and generalisable across the whole of the UK.

treatment regimens. ${ }^{1}$ Professional associations and societies have also supported the utilisation of biosimilars but to a different extent. The rate of uptake of biosimilars has been keenly debated among the stakeholders in different specialties. ${ }^{2-4}$ Healthcare professionals (HCPs) have been surveyed on their knowledge, attitude and practice towards biosimilars in the UK. ${ }^{5}$ The results of that survey showed a good understanding and awareness of UK HCPs of biosimilars with a significant variation in attitude. This difference was reflected in their uptake of the corresponding biosimilars.

A survey of the literature revealed many surveys about HCPs' knowledge, attitude and experience towards biosimilars, ${ }^{6-17}$ but only one in-depth study investigating the barriers to uptake. ${ }^{18}$ This study was undertaken in 
non-UK setting. Thus, the main aim of this study was to investigate in more detail the barriers and facilitators to the use of biosimilars by UK HCPs.

\section{METHODS}

A qualitative research method using face-to-face semistructured interviews was used to elucidate in-depth interviewee's knowledge, perceptions and attitudes to biosimilars. A purposive convenience sampling of HCPs within the West Midlands hospitals with expertise in the clinical specialties of diabetes mellitus, ulcerative colitis, Crohn's disease, rheumatoid arthritis, ankylosing spondylitis and psoriatic arthritis where insulin glargine, infliximab and etanercept were prescribed was used. These included prescribing HCPs in different professions and specialties in secondary care settings (consultants, practice nurses, nurse prescribers and independent prescriber pharmacists). In the UK, pharmacists and nurses can undertake further training to become registered independent non-medical prescribers. Independent non-medical prescribers can legally prescribe any medicine within their sphere of competence which includes biologics. ${ }^{19}$

As part of the National Health Service (NHS) research approval process, an application was made via the NHS Health Research Authority to all 14 acute hospitals in the West Midlands. The research and development departments of seven of these sites (50\%) gave approval for the research to be conducted in their hospitals. Stakeholders from these seven hospitals were invited by electronic mail and/or telephone to a single $30 \mathrm{~min}$ interview during the period of June-November 2017. A snowballing technique was used with the interviewees who positively replied to the invitation being asked to name further professionals within the specialty, who prescribed biologics/biosimilars. HCPs' interviews took place at their offices. No incentives were offered to the participants who participated voluntarily. Specialty-specific semistructured interview guides were non-leading and non-judgemental and had been developed from an interpretation of the literature and a pilot with a small number of healthcare professionals and academics, and amended according to their comments and suggestions. The interview guides were designed to explore HCPs' knowledge and attitude towards biosimilars, prescribing practice of biosimilars in each specialty, the barriers to use of biosimilars and potential approaches to overcome these barriers. The interview guides were also informed by a review of the literature.

Before the interviews were conducted, the interviewees received a participant invitation letter, participant information sheets and consent forms. Written and verbal informed consents were obtained from all participants (before starting the study) who were assured of data confidentiality and their right to withdraw at any time. The interview schedule began with a brief statement in the form of summary points about the research objectives, why the research is being conducted and an overview of the questionnaires.
Semistructured interviews were conducted by MIA, a man, trained clinical pharmacist, PhD student. The interviews were digitally audio-recorded. Anonymised audio records were transcribed by an independent company. Transcripts were checked for accuracy following the transcribing. Data were analysed using thematic analysis by MIA. ${ }^{20}$ The analysis consisted of six stages: familiarisation with the data, generating initial codes, searching for themes, reviewing themes, defining and naming themes and producing the report. The interviews were analysed using NVivo 11 Pro to facilitate the analysis. The study was approved.

\section{Patient and public involvement}

No patients or members of the public were involved in this study, but the questions were influenced by the results of the authors' previously published patients' web survey. ${ }^{21}$

\section{RESULTS}

Out of 99 recipients of invitation letters, 26 potential participants responded. Four participants withdrew before the interview day due to lack of time. A total of 22 semistructured interviews were conducted in person with the HCPs from five hospital trusts (the University Hospital of North Midlands NHS Trust, the Staffordshire and Stoke on Trent Partnership NHS Trust, the Royal Wolverhampton NHS Trust, the Heart of England NHS Trust and the University Hospitals Coventry and Warwickshire NHS Trust). Data saturation was achieved. Table 1 shows the demographic characteristics of interview participants.

\section{Major themes}

Five main themes emerged from the semistructured interviews with HCPs: perception of biosimilars, attitude towards biosimilar prescribing, HCPs' views on the evidence base for biosimilars, facilitators to prescribing biosimilars and barriers to prescribing biosimilars.

\section{Perception of biosimilars}

All interviewed HCPs expressed an understanding of the concept of biosimilars. They believed that a biosimilar is a copy of the reference biological medicine. HCPs attributed the difference between biosimilars and generic medicines to the biological nature of biosimilars versus the chemical nature of generics, the difference in manufacturing processes and structure.

'They are, [biosimilars] on a parallel to generics, for other drugs but because they're biologically active substances, they obviously have to be a lot more care when they were developed...' (G5)

The main sources of 'first knowledge' of biosimilars were conferences, pharmaceutical industry representatives, scientific journals and colleagues.

\section{Attitude towards biosimilar prescribing}

The majority of HCPs were content to initiate biosimilars. A minority of rheumatology HCPs and diabetology HCPs 
Table 1 Demographic characteristics of the participants

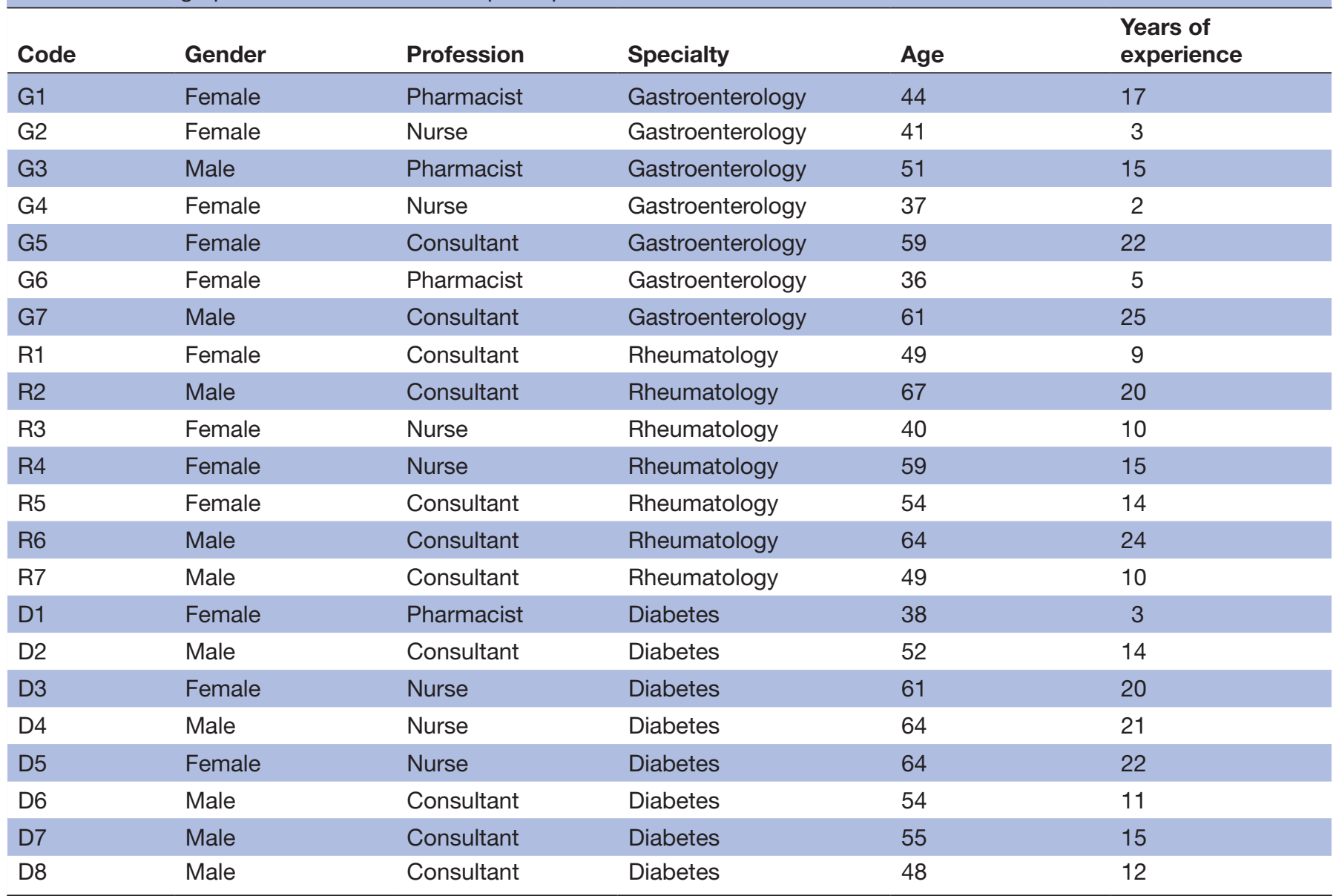

felt that they were under pressure from their organisation to initiate new patients on biosimilars. They felt they had limited options for giving new patients the choice between biosimilars and reference biological medicine.

'We've been forced in a way to put all our new patients onto a biosimilar.' (R2)

All gastroenterology HCPs and a minority of rheumatology HCPs were content to switch patients from a reference biological medicine to a biosimilar. For gastroenterologists, the availability of appropriate data, guidance from their professional associations and the experiences of colleagues in other trusts influenced their decision of whether or not to switch to a biosimilar.

Two rheumatology HCPs expressed the view that they were happier with initiation rather than switching. This view was based on concerns about disrupting the care of stable patients for purely economic reasons.

'Actually, I'm happier to initiate new patients than I am a switch. At a patient level, I think it's really tricky if you've got a really good response to an agent and we're asking people to switch for purely economic considerations.' (R1)

The majority of diabetology HCPs were reluctant to switch patients from the reference biological medicine to a biosimilar for cost reasons. They felt a switch requires long-term monitoring of patients and they are dealing with complicated cases for just a short period of time. Also, as the hospitals were not paying for insulin after the patient's discharge, they felt any switching process should be done by general practitioners in primary care settings as it would be the primary care budget that would benefit.

'I think that it would require close monitoring to switch your patients because as I say they don't produce exactly the same results' ... 'the hospital setting is not the most appropriate place to switch in terms of if we switch a patient and then we discharge them home there is going to need to be close follow.' (D1)

All HCPs who were comfortable with switching expressed the view that patients should be given the choice between biosimilars and reference biological medicine when switching. HCPs outlined two switching strategies, either an additional consultation, explaining the reasons for switching and the possibility of switching back to their reference agent, or sending out letters informing patients of the proposed switch.

'The gastroenterology consultants were happy for the patients to receive a letter and the emphasis was tell us if you don't like what we've told you otherwise you 
will automatically be switched next time you come in.' (G6)

'The rheumatology consultant wanted a very more sort of touchy-feely approach with his patients, he didn't want to lose their confidence and he very much wanted a personal clinic face-to-face appointment to talk about the switch and this is quite interesting.' (R5)

The majority of HCPs appeared to have a negative opinion and/or attitude towards the automatic substitution of the reference biological medicine with a biosimilar at the pharmacy level. A minority of HCPs believed that automatic substitution would be accepted in the next few years.

'Not currently, I think it will probably be the situation in five years' time when everybody has used them for a period of time and has the confidence in the interchangeability.' (G6)

About $50 \%$ of gastroenterology HCPs and rheumatology HCPs indicated that any cost savings should be shared between their department and the Clinical Commissioning Groups (CCG). Those HCPs believed that this 'gain share' would expand the services provided to the patients.

'I think these savings will come to the department because we've already negotiated that it'll fund an extra nurse. The patient will also get the benefit.' (R4)

In contrast, the remaining gastroenterology HCPs and rheumatology HCPs believed that cost savings would be for the CCGs. Those HCPs where there was no 'gain sharing' believed that biosimilars had a negative impact on their department due to increased workload associated with switching patients (including calling, sending letters and extra consultation).

'At the moment, with no gain sharing, it has a negative cost implication in that we're having to get people up who are switching.' (R1)

The majority of rheumatology and diabetology HCPs agreed that if the price of the reference biological agent became equivalent to the price of biosimilars, they would choose to prescribe the reference.

'Abasaglar@ has only got validity if it's cheaper. If you had the same price, what's the use of having biosimilars which are similarly priced? If Lantus ${ }^{\circledR}$ price becomes similar to Abasaglar ${ }^{\circledR}$, I would never prescribe Abasaglar®.' (D6)

\section{HCPs views on evidence base on biosimilars}

Gastroenterology HCPs expressed more confidence and/or fewer concerns than other specialists. They indicated that indication extrapolation was the main source of hesitance about biosimilar uptake, but this had been overcome.
'Indication extrapolation was the main reason that the British Society Gastroenterology were hesitant and the main reason why our clinicians were hesitant in gastroenterology, they requested to see trials in gastro patients before.' (G6)

Gastroenterology HCPs also suggested that adalimumab biosimilar uptake would be easier than infliximab biosimilars even if the indications were extrapolated from other specialties because of prior experience with infliximab.

'For adalimumab biosimilar, If the finances are agreed up front it will probably go 'wow'. I think because gastro made the move with Inflectra ${ }^{\circledR}$ they won't be hesitant with the adalimumab in the same way as they were because the concept has already been tried.' (G6)

By contrast, the majority of rheumatology HCPs had concerns about indication extrapolations. Rheumatology HCPs considered their patients were very sensitive with higher multimorbid risks than patients with ulcerative colitis. In some cases, they openly declared themselves to be more mistrustful of biosimilars than other specialists.

'Well I'd be very, very wary and I know there is another example isn't there of one of the existing biologics of extrapolation of infliximab, that's right yes, but I would be wary about accepting gastroenterology experience and extrapolating to rheumatoid patients'... 'We are very obsessive!! Very mistrustful and obsessive!!' (R7)

The majority of HCPs in all specialties felt multiple switching between a reference biologic and a biosimilar on the basis of cost alone to be irrational, with the potential for reducing the trust between patient and clinician. HCPs also expressed their preference to keep the patient on the biosimilar if the patient has no problems.

They were prepared to switch from biosimilars back to the reference biologic if they had efficacy or safety concerns.

'I would imagine with the workload that's gone into the switch between Remicade ${ }^{\circledR}$ and Inflectra ${ }^{\circledR}$ unless there was a significant cost saving I doubt that we would switch again because of the implications and the workload that it increased when we had to do it. I just don't think they'd like the instability of constantly switching drugs.' (G2)

'Even if they dropped their price to the equivalent or near the price of the biosimilar, we wouldn't go back.' (G3)

'I think that multiple switching is irrational because there's such a paperwork chase to change prescription that we wouldn't probably do that.' (R6)

Facilitator to prescribing biosimilars

Gastroenterology HCPs believed that the guidance from the British Society of Gastroenterology and the National 
Institute for Health and Care Excellence (NICE), experience from other trusts and the national registry are enough for using biosimilars. Others believed that they have switched almost all patients (with the exception of the reluctant patients or those with contraindications). Diabetologists thought that the number of patients using biosimilars would increase naturally.

'To use infliximab biosimilars, I think the data is there now to be honest with you, like I said the BSG have issued a guidance, NICE have issued a guidance, there have been quite a few Trusts throughout the UK who have done the switch, so I think the evidence is there and we are happy to switch to infliximab.' (G3)

'I don't think we need anything. I think it is increasing so we're seeing more patients, more patients are requiring basal insulin' ... 'I think naturally the prescription rates are increasing.' (D5)

In contrast, half of diabetology, rheumatology and some gastroenterology HCPs valued the availability of more supportive evidence on the efficacy and safety of biosimilars from other Trusts.

'Other trusts' experiences possibly influence my views. Because the trial data is very clinical and it's often when the drugs come out into real-life clinical situations that you get actual useful data.' (D3)

Determining who benefited from the cost savings was the main reason for the delay in including biosimilars in hospital formulary and their use. Some HCPs suggested that offering cost sharing with the department would influence their use of biosimilars.

'Biggest delay to introducing biosimilars into the Trust and into other Trusts as well have been political arguments over the savings and who is going to get them.' (G6)

'If they offer us a gain-share, then this would definitely influence the use.' (D4)

\section{Barriers to prescribing biosimilars}

The majority of HCPs indicated that the development of an unexpected adverse effect or the increase in the rate of side effects among patients locally or nationwide would inhibit them from prescribing biosimilars.

'If the patients did set against it; if you saw lots of bad side-effects; if it wasn't working with the client group for some reason. If you had more people not getting the benefit, then you wouldn't want to carry on.' (R3)

A minority of HCPs in different specialties believed that if a patient had a strong opinion against biosimilars, they would not switch them.

'If patients really didn't want to do it because you do have to explain to a patient when you give it the biosimilar and if they didn't want to use it that's totally up to them and it rules it out completely because a patient has the choice at the end of the day.' (D1)

The majority of rheumatology HCPs mentioned the administration device of biological medicine as an important factor or barrier to prescribing. Complicated, unsuitable and non-user-friendly devices were the main causes of errors and reluctance by patients. A rheumatology HCP also outlined that some patients were not switched from the reference etanercept (Enbrel) to the biosimilar (Benepali) either due to the unavailability of all dosage strengths of Benepali or being allergic to the preservative available in the pens.

'We can't switch all patients because Benepali ${ }^{\circledR}$ don't do a $25 \mathrm{mg}$ syringe and they also don't do the $25 \mathrm{mg}$ vial without the preservatives. Because we've got some patients allergic to the preservative and so they're on the vials.' (R4)

Interestingly, the majority of rheumatology HCPs believed that Benepali injecting pen was better than Enbrel's pen due to its ease of use, fewer steps for dosage administration and being less painful. These factors lead to some patient on Enbrel requesting Benepali.

"A lot of the patients are finding the Benepali ${ }^{\circledR}$ pen a lot easier because they just push it down, so they haven't gotten to use their thumb to press the button.'

The majority of diabetology HCPs were familiar with insulin glargine administration devices and believed that the biosimilar (Abasaglar) pen device (Kwick pen) is very similar to the reference (Lantus) pen device (SoloSTAR pen).

\section{DISCUSSION}

The findings of the study indicated that the majority of HCPs in all specialties shared some similarity in knowledge, opinions and attitudes on biosimilar prescribing practice. These similarities included: their good level of knowledge, contentment (happiness) to initiate newly diagnosed patient on biosimilars without giving patient the choice, disagreement with automatic substitution of biosimilars at the pharmacy level and disagreement with multiple switching for cost reasons. They differed on their acceptance of switching to biosimilars, the pathway of switching and how to inform the patient about switching, acceptance of indication extrapolation and cost saving and sharing. The findings from this study also revealed that real-world data about safety and efficacy and financial aspects of the Trust had the potential to optimise biosimilar utilisation.

This study has both strengths and limitations. It is the first in-depth study investigating the facilitators and barriers of biosimilar prescribing among UK specialty HCPs. It is potentially limited by the inclusion criteria for the semistructured interviews which might have resulted 
in participating specialty HCPs in gastroenterology, rheumatology and diabetology being skewed towards those who tend to be prescribing biosimilars. This might have resulted in participants being primarily early adopters of new therapies, with different perceptions of biosimilars to HCPs not currently prescribing biosimilars. Furthermore, it is highly likely that those who accepted the interview are already engaged in the use of biosimilars and 'aligned' with the questions raised. Due to the small sample size and the diversity of specialties and organisational background, it was not possible to identify a difference in attitude associated with demographics.

Like this study, several other studies have shown HCPs had a good understanding of the concept of biosimilars, used similar sources of information about biosimilars (eg, conferences, online information, medical representatives, industry, scientific journal, professional bodies guidelines and colleagues), ${ }^{5} 922$ were more prepared to initiate than to switch patients to and were concerned or uncomfortable with a pharmacist auto-substituting a patient's biological medicine. ${ }^{7101322}$

The main areas of differences in views and attitudes between HCPs of different specialties were acceptance of switching to biosimilars, data and indication extrapolation from brand (reference) biologics and attitudes to cost savings and sharing those savings.

Gastroenterology HCPs were more open to switching established patients to biosimilars than rheumatology and diabetology HCPs, explaining that the availability of data supporting switching, guidance from professional bodies and associations and experience from other Trusts and countries encouraged them to switch patients. Rheumatology HCPs were happier to initiate patients on a biosimilar rather than to switch, possibly due to them using less infliximab than their gastroenterology colleagues, and the fact that the molecule they used more frequently, etanercept, only recently became available as a biosimilar (March 2016). In contrast to gastroenterologists, they wanted more real-life data on switching and a clear pathway for switching to overcome their concerns about biosimilars; the lack of guidance from their professional association may also have had some influence.

Diabetology HCPs were reluctant to switch to a biosimilar for cost reasons, primarily because they dealt in the short term with complicated patients in the hospitals then; once controlled, they discharge them to primary care. Thus, as the hospitals are only paying for the insulin in the short term and not for the total duration of treatment, the diabetologists felt that general practitioners should do the switching as they have both the capability to monitor patients and it would be their budget that benefited. This links to the attitude of some other HCPs who were only prepared to switch if the savings directly benefited their department. This reflects results from previous studies by Chapman et al, Hemmington et al and O'Callaghan et al. ${ }^{5223}$

In terms of the pathway and how best to inform patients about potential switches, gastroenterologists were satisfied with indirect contact, simply informing the patient by post, whereas rheumatology preferred face-to-face consultations, believing that this gave them a chance to relieve any patient concerns. This reflects the National Rheumatoid Arthritis Society position that switching patient to biosimilars can be alarming for patients unless there is clear discussion and agreement between the consultant/ prescriber and the patient with both risks and benefits explored and explained. ${ }^{24}$

The difference between the positions of specialties on switching could be attributed to the difference in the settings, administration device and method of administration of the biologic. Gastroenterology HCPs frequently used infliximab, administered to inpatients as an intravenous infusion for both the brand (reference) biologic and the biosimilar; patients may not experience any significant difference as there is no change in mode of administration. By contrast, rheumatology HCPs mainly used etanercept and relatively little infliximab. Etanercept is used in the outpatient or home setting, self-administered and marketed in different administration devices; thus, the patient would notice the difference in the shape of the device and the mechanism (steps) of self-administration and there are more likely to be concerns to be addressed by the treating HCPs. Results from the study by Chapman et al showed that the less complicated, userfriendly with less number of steps for preparation of the dose were the most acceptable administration devices. ${ }^{25}$ The unavailability of similar dosage form or strength was responsible for some patients not being switched from Enbrel to Benepali. The good design and ease of use of the administration device of Benepali led some patients to request to be switched to the biosimilar. This result was in line with Thakur et al's study results which showed that France, Germany, Italy, Spain and UK rheumatology nurses and rheumatoid arthritis patients would prefer Benepali autoinjector, as it is easier to operate and more intuitive to use compared with Enbrel MyClic autoinjector. ${ }^{26} 27$

Diabetology HCPs were less concerned about the administration device of insulin glargine biosimilar (Abasaglar), as Abasaglar was launched in Lilly devices which were already in use as the prefilled Kwik pen and the reusable Savvio pen. These devices are similar to Lantus administration devices, prefilled and reusable SoloSTAR pens. ${ }^{28}$ Wilkins et al's study results showed only $1.5 \%$ of surveyed patients with diabetes would be concerned about the design administration device if they were offered biosimilar insulin glargine. ${ }^{29}$ Diabetology HCPs expressed the view that patients with diabetes had the concept and the technique of insulin administration devices and only slight differences existed between these devices. This result was in line with New Zealand Pharmaceutical Management Agency that switching from Lantus to Abasaglar would not necessarily be problematic for patients with diabetes as there is a precedent for switching between brands of insulin and these are essentially biosimilars. ${ }^{30}$ 
Despite the fact that biosimilar indication extrapolation has been a source of hesitancy and debate among HCPs ${ }^{31}$ gastroenterology HCPs expressed that their experience with indication extrapolation of infliximab biosimilars from rheumatology to gastroenterology was successful. They suggested that, given this positive experience, they were now more positive and open towards the concept of indication extrapolation, which could lead to a fast uptake of upcoming adalimumab biosimilars. Danese $e t a l$ s study showed that $25 \%$ of European gastroenterologists were concerned about indication extrapolation. ${ }^{14}$ Rheumatology HCPs were less confident and dissatisfied with indication extrapolation from other specialties and believed that biosimilars should be tested for each indication. These HCPs thought that there are differences in mechanism of action, dose, frequency and the multimorbidity of the diseases when using a biologic such as infliximab in rheumatoid arthritis and Crohn's disease. Grabowski et al $l$ s study showed that only $32 \%$ of Canadian rheumatologists were confident in indication extrapolation. ${ }^{10}$ In a similar position, diabetology HCPs also expressed their dissatisfaction with indication extrapolation of the reference (Lantus) to the biosimilar (Abasaglar); some diabetology HCPs expressed that they had a bad experience with previous insulin biosimilars that have been withdrawn from the market such as Marvel Insulin.

HCPs whose department shared part of the savings with commissioners appeared content with using biosimilars and believed that biosimilar utilisation would improve their department and the service provided to the patients; As these departments had invested shared savings to fund extra nurse (biological nurse) that would help the department and the patients.

In contrast, HCPs whose department had not received a share of the cost savings believed these savings would go to the CCG. This latter group felt biosimilar utilisation had a negative impact on their department, department resources and to the service provided to the patients because the switching process meant HCPs were running extra clinics and meeting with patients more frequently, with monitoring and more associated paperwork. This is similar to Regional Medicines Optimisation Committees discussion summary in 2017 that stated increased workload for biosimilar switching is one of the challenges facing switching in a department and there may be lack of additional staffing to handle it. ${ }^{32}$ HCPs also weighted cost savings and sharing as important factors influencing biosimilar use; the more cost saving associated with a biosimilar, the more the chance of choosing this biosimilar. A recent budget impact analysis in the UK estimated that the entry of new anti-TNFs (tumor necrosis factors) would result in a cumulative savings of $£ 285$ million by 2020. ${ }^{33}$ Hospitals and department negotiations with commissioners about 'gain share' could either enhance or delay the uptake of biosimilars. If gain share was possible this would incentivise HCPs to use these biosimilars if they were offered to the department. By contrast, if they were not offered a share of savings, biosimilars would be considered to have a negative impact on their departments and utilise department's resources.

Several barriers to biosimilar utilisation were identified in this study. Safety and efficacy concerns were the most commonly raised barriers that might prevent HCPs from considering prescribing biosimilars. The lack of longterm safety data of biosimilars and the complex nature of the protein raised HCPs' concerns about unexpected adverse events, increasing the incidence of serious side effect or increased development of infections. This result was in line with the study result of Dylst $e t a l$, Narayanan and Nag, Chapman et al and O'Callaghan et al. ${ }^{515} 1822$

Patient's opinions and reluctance to accept biosimilars on the basis of cost alone was identified as a barrier to the uptake of biosimilars by some specialty HCPs. A patient on a reference biological medicine who has been offered to be switched to a biosimilar has the right to refuse to be switched even after a consultation with the treating HCPs. Consent should be taken from the patient before switching process takes place. Waller $e t a l$ s study showed that $56 \%$ of German rheumatoid patients reported by rheumatologists were unhappy to be switched to biosimilars for non-clinical reasons. ${ }^{34}$ Similarly, Sullivan et $a l$ s study showed that $43 \%$ of German gastroenterology patients reported by gastroenterologists were unhappy to be switched to biosimilars for non-clinical reasons. ${ }^{35}$

\section{CONCLUSION}

This study showed that UK HCPs had good understanding of biosimilars with subtle difference between specialties in their attitude to using biosimilars. Gastroenterology HCPs were more open and less concerned than rheumatology and diabetologists towards biosimilar initiation and switching. Safety and efficacy concerns, patients' opinion and how cost savings were shared were the identified barriers to considering prescribing biosimilars. Real-life data and financial incentives were the suggested facilitators to increase biosimilar utilisation.

Acknowledgements The authors would like to acknowledge all participants who took part in the face-to-face interviews. MIA was sponsored by the Higher Committee for Education Development in Iraq.

Contributors All authors have contributed to this study and all authors reviewed and approved the final version of the manuscript. MIA participated in the study design, data collection, interpretation of results, prepared the manuscript draft and performed all analytical testing and manuscript review. RWF participated in the study design, interpreted the results and reviewed the manuscript and corrected the final version of the manuscript. SRC designed the study, interpreted the results and reviewed the manuscript and corrected the final version of the manuscript. All authors had full access to all of the data in the study and can take responsibility for the integrity of the data and the accuracy of the data analysis.

Funding The authors have not declared a specific grant for this research from any funding agency in the public, commercial or not-for-profit sectors.

Competing interests None declared.

Patient consent Obtained.

Ethics approval Independent Peer Review Committee at Keele University (Reference 421) and Health Research Authority Committee London - Surrey Borders (Reference 17/L0/0084) 
Provenance and peer review Not commissioned; externally peer reviewed.

Data sharing statement Given the sensitive nature of the study interviews, raw data are not publicly available. Interested persons may contact the corresponding author for more information.

Open access This is an open access article distributed in accordance with the Creative Commons Attribution Non Commercial (CC BY-NC 4.0) license, which permits others to distribute, remix, adapt, build upon this work non-commercially, and license their derivative works on different terms, provided the original work is properly cited, appropriate credit is given, any changes made indicated, and the use is non-commercial. See: http://creativecommons.org/licenses/by-nc/4.0/.

\section{REFERENCES}

1. NICE. Biosimilar medicines. 2016. https://www.nice.org.uk/advice/ ktt15/resources/biosimilar-medicines-pdf-58757954414533

2. The British Society of Gastroenterology. BSG Guidance on the use of Biosimilar Infliximab CT-P13 in Inflammatory bowel disease. 2016. http://www.bsg.org.uk/images/stories/docs/clinical/guidance/bsg_ infliximab_guidance_16.pdf [Accessed 22 Dec 2017].

3. The British Society of Rheumatology, 2017. British Society for rheumatology position statement on biosimilar medicines http:// www.rheumatology.org.uk/includes/documents/cm_docs/2017/r/ revised_bsr_biosimilars_position_statement_jan_2017.pdf [Accessed 22 Dec 2017].

4. The British Association of Dermatologists. British association of dermatologists' position statement on biosimilars. 2017. http:// www.bad.org.uk/shared/get-file.ashx?id=3615\&itemtype=document [Accessed 22 Dec 2017].

5. Chapman SR, Fitzpatrick RW, Aladul MI. Knowledge, attitude and practice of healthcare professionals towards infliximab and insulin glargine biosimilars: result of a UK web-based survey. BMJ Open 2017;7:e016730.

6. Azevedo VF, Felippe LR, Machado DM. Opinion of some Brazilian rheumatologists about biosimilars. Rev Bras Reumatol 2011;51:667-71.

7. Danese S, Fiorino G, Michetti P. Viewpoint: knowledge and viewpoints on biosimilar monoclonal antibodies among members of the European Crohn's and Colitis Organization. J Crohns Colitis 2014;8:1548-50.

8. Narayanan S, Liu L. Likelihood of use and perception towards biosimilars in rheumatoid arthritis arena: survey of Rheumatologists in European Union, Brazil, Japan and China. Value in Health 2013;16:A388-A389.

9. Akhmetov I, Farista R, Thimmaraju PK. A study to assess the awareness of the biosimilars among ukrainian physicians. Journal of Bioanalysis \& Biomedicine 2015;7:75-80.

10. Grabowski D, Henderson B, Lam D, et al. Attitudes towards subsequent entry biologics/biosimilars: A survey of Canadian rheumatologists. Clin Rheumatol 2015;34:1427-33.

11. Tanabe K, Sugimoto N, Fujimoto $Y$. A web-based survey to investigate the extent of awareness and understanding for biosimilar among japanese physicians and pharmacists. Value Health 2015;18:A658

12. Beck M, Michel B, Rybarczyk-Vigouret MC, et al. Rheumatologists perceptions of biosimilar medicines prescription: findings from a french web-based survey. BioDrugs 2016;30:585-92.

13. Beck M, Michel B, Rybarczyk-Vigouret MC, et al. Knowledge, behaviors and practices of community and hospital pharmacists towards biosimilar medicines: Results of a French web-based survey. MAbs 2017;9:384-91.

14. Danese S, Fiorino G, Michetti P. Changes in Biosimilar Knowledge among European Crohn's Colitis Organization [ECCO] members: an updated survey. J Crohns Colitis 2016;10:1362-5.

15. Narayanan S, Nag S. Likelihood of use and perception towards biosimilars in rheumatoid arthritis: a global survey of rheumatologists. Clin Exp Rheumatol 2016;34:9.
16. Pasina L, Casadei G, Nobili A. A survey among hospital specialists and pharmacists about biosimilars. Eur J Intern Med 2016;35:e31-e33.

17. Cohen $\mathrm{H}$, Beydoun D, Chien D, et al. Awareness, knowledge, and perceptions of biosimilars among specialty physicians. Adv Ther 2017;33:2160-72.

18. Dylst $P$, Vulto $A$, Simoens $S$. Barriers to the uptake of biosimilars and possible solutions: a Belgian case study. Pharmacoeconomics 2014;32:681-91.

19. Department of Health. Prescribing by non-medical healthcare professionals. 2010. https://www.health-ni.gov.uk/articles/ pharmaceutical-non-medical-prescribing\#toc-2 [Accessed $19 \mathrm{Jul}$ 2018].

20. Braun V, Clarke V. Using thematic analysis in psychology. Qual Res Psychol 2006;3:77-101.

21. Aladul MI, Fitzpatrick RW, Chapman SR. Patients' understanding and attitudes towards infliximab and etanercept biosimilars: result of a uk web-based survey. BioDrugs 2017;31:439-46.

22. O'Callaghan J, Bermingham M, Leonard M, et al. Assessing awareness and attitudes of healthcare professionals on the use of biosimilar medicines: A survey of physicians and pharmacists in Ireland. Regul Toxicol Pharmacol 2017;88:252-61.

23. Hemmington A, Dalbeth $N$, Jarrett $P$, et al. Medical specialists' attitudes to prescribing biosimilars. Pharmacoepidemiol Drug Saf 2017;26:570-7.

24. NRAS. NRAS position paper on biosimilar medicines - Revised June, 2016. 2016. https://www.nras.org.uk/data/files/Publications/NRAS\% 20Revised\%20position\%20paper\%20Final\%206.6.16.pdf

25. Chapman SR, Fitzpatrick RW, Aladul MI. What drives the prescribing of growth hormone preparations in England? Prices versus patient preferences. BMJ Open 2017;7:e013730.

26. Thakur K, Biberger A, Handrich A, et al. Perceptions and preferences of two etanercept autoinjectors for rheumatoid arthritis: a new european union-approved etanercept biosimilar (benepali ${ }^{\circledR}$ ) versus etanercept (enbrel ${ }^{\mathbb{Q}}$ ) - findings from a nurse survey in Europe. Rheumatol Ther 2016;3:77-89.

27. Thakur K, Biberger A, Handrich A, et al. Patient perceptions and preferences of two etanercept autoinjectors for rheumatoid arthritis: findings from a patient survey in Europe. Rheumatol Ther 2016;3:245-56.

28. Hooker N. London Medicines Evaluation Network Review Answers to commonly asked questions about biosimilar versions of insulin glargine. 2015. https://www.sps.nhs.uk/wp-content/uploads/ 2015/10/LMEN20review20on20insulin20glargine20biosimilars.pdf [Accessed 22 Jan 2018].

29. Wilkins AR, Venkat MV, Brown AS, et al. Patient perspectives on biosimilar insulin. J Diabetes Sci Technol 2014;8:23-5.

30. Pharmac. Supply of insulin glargine. 2016. https://www.pharmac. govt.nz/news/rfp-2016-02-22-insulin-glargine/ [Accessed 22 Jan 2018].

31. Ebbers HC, Chamberlain P. Controversies in establishing biosimilarity: extrapolation of indications and global labeling practices. BioDrugs 2016;30:1-8.

32. NHS England. Regional medicines optimisation committees: discussion summary. 2017. https://www.sps.nhs.uk/wp-content/ uploads/2017/09/RMOC-North-28th-June-discussion-summaryBiosimilars.pdf [Accessed 18 Jan 2018].

33. Aladul MI, Fitzpatrick RW, Chapman SR. The effect of new biosimilars in rheumatology and gastroenterology specialities on UK healthcare budgets: Results of a budget impact analysis. Res Social Adm Pharm 2018:S1551-7411.

34. Waller J, Sullivan E, Piercy J, et al. Assessing physician and patient acceptance of infliximab biosimilars in rheumatoid arthritis, ankylosing spondyloarthritis and psoriatic arthritis across Germany. Patient Prefer Adherence 2017;11:519-30

35. Sullivan E, Piercy J, Waller J, et al. Assessing gastroenterologist and patient acceptance of biosimilars in ulcerative colitis and Crohn's disease across Germany. PLoS One 2017;12:e0175826. 